\title{
Otra revista científica médica ¿se justifica?
}

\section{Another medical journal it's justified?}

\section{- Diego Soto}

'Profesor emérito, Ortopedia Oncológica, Instituto Nacional de Cancerología ESE (Bogotá, Colombia).

Hasta hace relativamente no muchos años, la bibliografía médica colombiana no se distinguía por ser muy amplia, ni tampoco por ser de obligada consulta, al menos dentro del concierto latinoamericano. Por ventura, poco a poco y con el tiempo, las pocas publicaciones científicas que había se volvieron numerosas, muy importantes y de una calidad extraordinaria la mayoría de las veces. Se dio un gran paso desde el grupo de revistas científicas, que, de inmediato, se dividieron en dos: las de índole quirúrgica, que se referían tan solo a aquellas especialidades en las que la cirugía tenía su papel primordial, y las no quirúrgicas, que se involucraban todas dentro de la medicina interna.

De este grupo, comenzaron a aparecer las de cardiología, las de las enfermedades del aparato respiratorio, y, de allí, se pasó a las de gastroenterología y nefrología. Pioneros de ellas lo fueron eminentes internistas en la época del "médico internista" que abarcaba, o debería abarcarlo, todo de la medicina interna, para ver de lo que somos testigos hoy y es que no solamente en número, sino en calidad, y de acuerdo con las múltiples especialidades médicas, nuestra bibliografía colombiana se volvió grande e importante.

El doctor Andrés Felipe Cardona es el editor jefe de la hoy constituida nueva Revista Colombiana de Hematología y Oncología; hablar de sus méritos personales y de su preparación científica es absolutamente innecesario, porque, no obstante su juventud, ya es un afamado médico que campea en estas dos especialidades o subgrupos con gran y reconocida eficiencia, además de la experiencia en publicaciones como la revista del Instituto Nacional de Cancerología, en la cual colaboró por muchos años. Se separaron un día, el doctor Cardona y su grupo de las publicaciones de la medicina interna, y hoy empiezan con respeto y con expectativa general en el número primero de la hematología propiamente dicha y en el muy proceloso campo de la oncología.

Hasta hace muy poco tiempo, todo caía en el campo de las anemias, de los grupos sanguíneos, y, en cuanto a la oncología, de las leucemias, mielomas, linfomas y tumores sólidos. Hoy vemos qué avance tan inusitado tiene esta especialidad, con un crecimiento científico ejemplar, que ayuda de qué manera a la medicina en el proceso de solucionar tantos problemas, aclarando patologías hemáticas y demostrando que ya no son algunas entidades exóticas, sino enfermedades del diario común. Por ejemplo, es verdaderamente digno de destacarse el estudio y conocimiento de la patogenia de la hemofilia, y, de otro lado, las clasificaciones dentro de las anemias que hoy aclaran muchas confusiones y dudas. No nombremos más avances reconocidos, porque se haría interminable.

Con toda franqueza, reconozco que se me ha hecho una enorme distinción y honor al pedirme que yo fuera el escritor de este editorial que da bienvenida a la revista científica. Personas muchísimo más calificadas que yo debieran estar escribiendo este texto, comoquiera que reconozco estar yo, en cuanto a conocimiento se refiere, a distancias siderales en el campo y en los temas de la publicación a la que nos venimos refiriendo. Quizás acudieron a mí por mi reconocida experiencia como escritor médico en temas de patología traumática y ortopedia, así como también en todo lo referente a la patología esqueleto-motora, aunque no para darles consejo ni mucho menos orientaciones, en cuanto soy consciente de que ustedes, como calificados especialistas, muy poco lo necesitan.

Felicito a los miembros y a las directivas de esta Sociedad por el gran paso dado, esperando que el éxito les llegue inexorablemente. Por cierto, no guardo la más mínima duda de que pronto esta revista llegará a ocupar un lugar de privilegio en el concierto de la medicina nacional, por la calidad científica y personal de quienes serán sus autores, de la Junta Directiva y de los que ocuparán sus páginas con escritos y artículos de la mayor importancia y actualidad en la ya mencionada especialidad.

Congratulaciones y felicitaciones a ellos y a la medicina nacional por este nuevo progreso. 